LÓPEZ HUGUET, M.L., «Reflexiones sobre un presunto supuesto de domicilium necessarium en Derecho romano: el domicilio del soldado», REDUR 5, diciembre 2007, pp. I29-I50. ISSN I695-078X

\title{
REFLEXIONES SOBRE UN PRESUNTO SUPUESTO DE DOMICILIUM NECESSARIUM EN DERECHO ROMANO: EL DOMICILIO DEL SOLDADO
}

\author{
$\mathrm{M}^{a}$ Luisa LóPEZ HUGUET ${ }^{*}$ \\ DOCTORA EN DERECHO \\ UNIVERSIDAD DE LA RIOJA
}

s u m a r i o

I. Introducción. II. Causas de la ausencia de regulación domiciliaria durante los períodos monárquico y republicano. III. Configuración del domicilio necesario durante el Imperio y hasta Justiniano: Análisis de la posesión de bienes en la patria. IV. Apéndice: La no reintegración del domicilium iure postliminii.

\section{r e $\quad$ s $u$ m e $n$}

La necesidad de un ejército de maniobra móvil, la progresiva "barbarización" del ejército y las solicitudes masivas del commeatus, hicieron necesario regular, a partir del siglo III-IV d. C., el régimen domiciliario de los soldados, estableciéndose la presunción iuris tantum de que el soldado conservaba su primitivo domicilio si poseía bienes en el lugar del que había salido para prestar su servicio militar. Sólo cuando dicha presunción se destruía, se le asignaba un domicilio donde se encontraba destinado. Por otro lado, cuando el soldado era capturado por el enemigo, perdía su domicilio primitivo y no podía recuperarlo por el postliminio.

\section{Introducción}

Las fuentes jurídicas atestiguan que la determinación del lugar donde una persona quería fijar o constituir su domicilio dependía de su singularis voluntas, de su destinatio animi, es decir, que el individuo era libre de elegir su lugar de domiciliación y podía establecerse donde quisiera salvo que, de forma expresa, le estuviera prohibido como claramente expone Marcelo: 
D. 50.I.3I (Marcelus, libro I. Digestorum): nihil est impedimento, quominus quis, ubi velit, habeat domicilium, quod ei interdictum non sit ${ }^{\mathrm{I}}$.

Esta libertad se consideraba tan esencial que no podía ser restringida por una disposición de derecho privado de manera que, si se hacía un legado bajo la condición de un determinado domicilio, según Papiniano, esta condición se reputaba no escrita:

D. 35.I.7I(69) \2 (Papinianus, libro XVII. Quaestionum): Titio centum relicta sunt ita: "ut a monumento meo non recedat", vel: "uti in illa civitate domicilium habeat"; potest dici, non esse locum cautioni, per quam ius libertatis infringitur".

Pero si la doctrina ha aceptado de forma unánime, como elemento esencial en la constitución del domicilio, la summa libertas personae sobre la elección del lugar donde quería domiciliarse $e^{3}$ los autores también han constatado que, en determinadas ocasiones,

\footnotetext{
* El presente artículo constituye una adaptación del capítulo III de la monografía Limitaciones a la libertad domiciliaria en Derecho romano que será próximamente publicada en la editorial Dykinson.

' En el mismo sentido, D. 50.I.27\2 (Ulpianus, libro II. ad Edictum): Celsus libro primo Digestorum tractat, si quis instructus sit duobus locis aequaliter, neque hic, quam illic minus frequenter commoretur, ubi domicilium habeat, ex destinatione animi esse accipiendum; ego dubito, si utrubique destinato sit animo, an possit quis duobus locis domicilium habere; et verum est habere, licet difficile est, quemadmodum difficile est, sine domicilio esse quequam. Puto autem et hoc procedere posse, si quis domicilio relicto naviget, vel iter faciat, quaerens, quo se conferat, atque ubi constituat; nam hunc puto sine domicilio esse; D. 50.I.22『2 (Paulus, libro I. Sententiarum): Municipes sunt liberti et in eo loco, ubi ipsi domicilium sua voluntate tulerunt; C. I. Io.39(40).6 (Impp. Diocletianus et Maximianus AA. et CC. Marecllino): Privilegio speciali civitatis non interveniente, tantum originis ratione ac domicilii voluntate ad munera civilia quemque vocari certissimum est.

${ }^{2}$ GLÜCK, C.F., Ausführliche Erläuterung der Pandecten nach Hellfeld: ein Commentar, Vol. VI, Erlangen, I80o, pág. 269; SAVIGNY, F., Sistema de Derecho romano actual, (trad. esp. de J. Mesía y M. Poley), $2^{a}$ edición, T. VI, Madrid, I924, pp. I55-156; ChAVAnES, H., Du Domicile, Paris, i863, p. 60; RousSel, F., Du domicile, en droit romain. De la formation des conventions, en droit international privé, Paris, I878, p. 27; GILIBERTI, G., Servus quasi colonus. Forme non tradizionali di organizzazione del lavoro nella società romana, Napoli, I98I, pp. I50; LICANDRO, O., Domicilium habere. Persona e territorio nella disciplina del domicilio romano, Torino, 2004, p. 325; GAGLIARDI, L., Mobilità e integrazione delle persone nei centri cittadini romani. Aspetti giuridici. I. La classificazione degli incolae, Milano, 2006, p. 390.

${ }^{3}$ GLÜCK, Ausführliche Erläuterung der Pandecten nach Hellfeld: ein Commentar, Vol. VI, cit., p. 265 y p. 277: «In der Regal häng es nun von eines jeden frenen Willen ab, einen Wohnort zu wählen, wo es ihm gefällt, und also auch sein bisheriges Domicilium wieder zu veränbern»; GASPARD, A., Recherches sur l'incolat, le droit de bourgeoisie et le domicile, Paris, I85I, p. I4: «Il faut donc qu'il y ait volonté de s'établir dans un lieu, et résidence dans ce lieu»; ChavanES, Du Domicile, cit., p. 56 y p. 6o: «C'est le lieu où quelqu'un réside constamment, qu'il a choisi librement comme centre de ses affaires et de ses rapports de droit... la liberté de la volunté est donc, en principe, une condition essentielle pour qu'il y ait domicile»; RousSEL, $D u$ domicile, en droit romain. De la formation des conventions, en droit international privé, cit., p. 27: «En principe, le domicile dépend du libre choix de la personne. A la différence de l'origo que impose un rapport de dépendance entre une cité et un individu, le domicile ne rattache à une ville que l'homme qui y consent»; DE RUGGIERO, E., La patria nel diritto pubblico romano, Roma, I92I, p. I78; SAVIGNY, Sistema de Derecho romano actual, T. VI, cit., p. I55: «La constitución del domicilio con sus consecuencias jurídicas resulta de la voluntad libre, unida con el hecho de la habitación... La libertad se considera tan esencial que no puede ser restringida por una disposición de derecho privado»; BRUGI, B., Istituzioni di Diritto Romano, $3^{\mathrm{a}}$ edición, Torino, I926, pp. 70-7I: «D’altra parte il domicilium, sebbene di regola voluntariamente stabilito ove a ciascuno piaccia, semprechè alla voluntà si accompagni il fatto...»; TEDESCHI, V., «Contributo allo studio del domicilio in Diritto romano», en R.I.S.G., I, I932, pp. 213-2I4: «Ciò importa nell'individuo la volontà di rimanere nel luogo del domicilio»; SANTALUCIA, B., I «libri opinionum» di Ulpiano II, Milano, I97I, p. IO2: «Nel diritto classico, come è noto, trovava pieno riconoscimento il principio della libertà di domicilio»; DE MARTINO, F., Storia della Costituzione Romana, $2^{\text {a }}$ edición, Napoli, I972, vol. III, p. 292: «Incola è perciò colui, che ha volontariamente e
} 
una persona, en virtud de su peculiar status, podía quedar sujeta a un domicilio necesario, impuesto, forzoso, relativo, legal u obligatorio, variada terminología con la que ponen de relieve que la fijación del domicilio se había efectuado, en mayor o menor medida, sin tener en cuenta la voluntad o intención del afectado ${ }^{4}$.

Entre estas excepciones al domicilium liberum, a través de la pluralidad terminológica antes expuesta, los autores hacen referencia a la obligación impuesta por el Derecho público a quienes desempeñaban cargos públicos de tener el domicilio en el lugar donde ejercían el mismo. Éste fue el caso de los senadores, obligados desde finales de la República a residir en la capital, debido al continuo incremento de senadores provinciales que tenían su domicilio fuera de Romá; o el de los magistrados y decuriones locales, cuya

stabilmente fissato la sua sede in un determinato comune, senza esservi nato... »; PORTILLO MARTIN, R., Incolae, Córdoba, I983, p. 30: «Existe una total libertad de elección sobre el lugar en el que una persona quiera domiciliarse»; THOMAS, Y., «Origine» et «Commune Patrie». Étude de droit public romain ( 89 av. J.-C. - 212 ap. J.-C.), Paris-Rome, I996, p. 46: «Le domicile se défine comme libre en ce qu'il... ressortit à la pure subjectivité individuelle»; BACCARI, M.P., Cittadini popoli e comunione nella legislazione dei secoli IV-VI, Torino, I996, p. 88 y p. III: «A differenza del domicilium che, come è più volte sottolineato nelle fonti, dipende dalla voluntà, l'origo dipende dalla veritas naturae»; LiCANDRo, Domicilium habere. Persona e territorio nella disciplina del domicilio romano, cit., p. 370, quien también reconoce la libertad domiciliaria clásica.

${ }^{4}$ GLÜCK, Ausführliche Erläuterung der Pandecten nach Hellfeld: ein Commentar, Vol. VI, cit., p. 265, habla genéricamente de «domicilio necesario»; GASPARD, Recherches sur l'incolat, le droit de bourgeoisie et le domicile, cit., pp. I5-I9, habla con carácter general de «domicile de dépendance»; CHAVANES, Du Domicile, cit., pp. 65-66, de «domicile nécessaire»; ROUSSEL, Du domicile, en droit romain. De la formations des conventions, en droit international privé, cit., pp. 29-34, prefiere la expresión «domicile présumé ou imposé par la loi»; SAVIGNY, Sistema de Derecho romano actual, T.VI, cit., pp. I56-I57, distingue en materia de domicilio obligatorio, entre: el domicilio impuesto por el derecho público con ocasión de un empleo público o una pena y el domicilio relativo, aquél determinado por las relaciones existentes entre dos personas; BRUGI, Istituzioni di Diritto Romano, cit., p. 7I, habla de «domicilio necesario»; PLESCIA, J., «Conflict of Laws in the Roman Empire», en Labeo, 38, I992, I, p. 37, habla de «domicile operation of law»; THOMAS, «Origine» et «Commune Patrie». Étude de droit public romain, cit., pp. 49-52, se refiere al domicilio obligatorio como «domicile forcé»; LICANDRO, Domicilium habere. Persona e territorio nella disciplina del domicilio romano, cit., pp. 34I ss., habla genéricamente de «domicilium necessarium», si bien precisa que estamos ante una disputa terminológica carente de relieve sustancial y desconocida por los romanos.

${ }^{5}$ En el Imperio, sin embargo, está obligación se atenuó hasta convetirse, en ambas partes del Imperio, en una residencia a los solos efectos de mantener vigentes los privilegios vinculados a la dignidad senatorial. Finalmente la separación entre el Senado y la aristocracia senatorial provincial, confirió legalmente a clarissimi y spectabiles plena libertad a la hora de elegir el lugar donde deseaban residir, sine commeatu, excluyéndoles de la Asamblea y, por tanto, de los privilegios ligados al domicilium dignitatis, reservados, a partir del siglo $\mathrm{V}$, sólo a los illustres que estaban obligados a residir en la capital respectiva si ejercían efectivamente un cargo de tal dignidad. Por todos, ScialoJA, V., «Sulla garanzia patrimoniale richiesta ai Senatori romani durante la repubblica», en B.I.D.R., II, I898, pp. 32 ss.; idem, «Le case dei decurioni di Tarento e dei senatori romani», en Studi Giuridici, II, I934, pp. 99-I05; TEDESCHI, «Contributo allo studio del domicilio in Diritto romano», cit., p. 232; ChastAgnol, A., «Le problème du domicile légal des sénateurs romains à l'époque impériale», en Mélanges offerts a L. S. Senghor, Dakar, I977, pp. 43 ss.; TALABERT, R.J.A., Le senate of the imperial Rome, Princeton, I984, p. 39 y pp. I3I ss.; LÖHKEN, H., Ordines Dignitatum. Untersuchungen zur formalen Konstituierung der spätaniken Führungsschicht, Köln-Wien, I982, pp. 55, p. 60 у pp. 95; SCHLINKERT, D., Ordo Senatorius und Nobilitas, Stuttgart, I996, p. 72 n. 47, pp. I32 ss. y pp. 227-229; GIGLIO, G., Il tardo impero d'occidente e il suo senato. Privilegi fiscali, patrocinio, giurisdizione penale, Napoli, I990, pp. 249 SS.; RUGGINI, L.C., «Il Senato fra due crisi», en AA.VV., Il Senato nella storia, Roma, I998, pp. 259 ss.; BURGARELLA, F.: «Il Senato di Costantinopoli», en AA.VV., Il Senato nella storia, Roma, I998, pp. 399 ss.; FERNÁNDEZ DE BUJÁN, Derecho Público Romano. Recepción, Jurisdicción y Arbitraje, cit., p. II2. 
obligación domiciliaria es constatada en los estatutos locales desde el siglo I a. C ${ }^{6}$.

Junto a estos ejemplos de domicilio obligatorio por razón del desempeño de un cargo público, Savigny afirmaba que también a todo empleado público era atribuido un domicilio necesario, afirmación que ha tenido una amplia acogida por parte de los autores?.

En nuestra opinión, sin embargo, reconociendo la inestimable aportación de la doctrina precedente en la labor de reconstruir la regulación jurídica del domicilio, el genérico planteamiento expuesto no está exento de imprecisiones que exigen, prima facie, una doble matización. Por una lado, se debe tener en cuenta que no todo cargo o empleo público comportaba una obligación domiciliaria, limitándose el "Estado", en ocasiones, a designar un deber de residencia", sobre todo, cuando el cargo era temporal. Por otro, aunque el propio hecho de la atribución indica, a priori, una limitación de la singularis voluntas, ello no significa, empero, que el Derecho público romano suplantara siempre la voluntad del empleado sino que, en ocasiones, se limitaba a asignar un domicilio ante la ausencia de otro libremente elegido.

\footnotetext{
${ }^{6}$ En tales estatutos locales se atribuía su observancia a los jefes locales. A finales del reino de Caracalla, el cumplimiento de la obligación fue encomendado al gobernador de la provincia, a través de su autorización para salir de la ciudad y de la concesión de una persecutio extaordinaria contra los decuriones que habían trasladado su domicilio a otra ciudad o se habían retirado al campo. No obstante, la flexibilidad del gobernador en la exigencia de la obligación domiciliaria, comportó que estas medidas fueran insuficientes para frenar el éxodo de los decuriones. Frente a ello, a partir de Constantino, la amplia discrecionalidad del gobernador provincial se ve limitada por un conjunto de leyes con las que se inicia, en ambas partes del Imperio, una rigurosa política domiciliaria mediante la extensión de la obligación domiciliaria a toda la clase curial y a los collegiati, la prohibición de los patrocinios fraudulentos y la prescripción del ejercicio acumulativo de los cargos en la ciudad de origen y en la ciudad de residencia. Por todos, LÉCRIVAIN, CH., s.v. «senatus municipalis», en D.S., IV.2, Paris, I877, pp. I200 ss.; SCIALOJA, «Sulla garanzia patrimoniale richiesta ai Senatori romani durante la repubblica», cit., pp. 32-33: idem, «Le case dei decurioni di Tarento e dei senatori romani», cit., p. 99-I05; ORMANNI, s.v. «curia, curiali», en N.N.D.I., V, Torino, I960, pp. 56-68; DE MARTINO, F., «Nota storica sui decurioni», en Rivista del Diritto della Navegazione, XXIX, I963, pp. 54-64; GAudemet, J., «Constantin et les curies municipales», en Études de Droit Romain, vol. II, Camerino, I979, pp. II2 Ss.; LANGHAMmER, W., Die rechtliche und soziale Stellung der Magistratus Municipales und der Decuriones in der Übergangsphase der Städte von sich selbstverwaltenden Gemeinden zu Vollzugsorganen des spätantiken Zwangsstaates (2.-4. Jahrhundert der römischen Kaiserzeit), SteinerWiesbaden, I97, passim; AвBOTT, F.F.-JOHNSON, A.C., Municipal administration in the Roman Empire, $2^{\mathrm{a}}$ edición, New York, I968, passim; RUPPRECHT, G., Untersuchungen zum Dekurionenstand in den nordwestlichen Provinzen des römischen Reiches, Kallmünz, I975, passim; REID, J.S.: The municipalities of the Roman Empire, Cambridge, I9I3, pp. 239 ss. y pp. 518 ss.; NuYENS, M., Le statut obligatoire des décurions dans le droit constantinien, Louvain, I964, passim.

${ }^{7}$ SAVIGnY, Sistema de derecho romano actual, T. VI, cit., pág. I56. En el mismo sentido, BRUGI, Istituzioni di Diritto Romano, cit., pág. 7I; SALGADO, J., «Contribución al estudio del “domicilium” en el Derecho romano», en R.D.P., LXIV (Enero-Diciembre I980), Madrid, I980, pág. 503. Cfr. MispouleT, J.B., La vie parlamentaire à Rome sous la République, Paris, I889, pág. 5I, sobre la imposibilidad de los tribunos del plebe de ausentarse un solo día de Roma; SUOLAHTI, J., The Roman Censors. A study on social structure, Helsinki, I963, pp. 52I-540, en relación con el domicilio de los censores; FABBRINI, F., su voz «tribuni plebis», en N.N.D.I., XIX, I973, pág. 798, sobre la obligación de presencia en Roma de los tribunos de la plebe; DELMAIRE, R., Largesses sacrées et res privata.

$L^{\prime}$ 'aerarium impérial et son administration $d u I V^{e}$ au $V I^{e}$ siècle, Paris, I989, pág. 50, sobre la obligación domiciliaria del comes rerum privatarum y del comes sacrum largitationum.

${ }^{8}$ Sobre la utilización del término Estado aplicado a Roma, FERNÁNDEZ DE BUJÁN, Derecho Público Romano. Recepción, Jurisdicción y Arbitraje, cit., pp. Iog ss.

${ }^{9}$ Cfr. Agudo RuIZ, A., Abogacía y abogados. Un estudio histórico-jurídico, Logroño-Zaragoza, I997, pp. 227-228; idem, El advocatus fisci en Derecho romano, Madrid, 2006, pp. 36, respecto al «deber de residencia» de los abogados del Tribunal del praefectus urbi de Constantinopla y del praefectus praetorio de Iliria.
} 
En este contexto merece una especial atención el domicilio del soldado en la medida en que, normalmente, sirve a los autores como ejemplo de la obligación domiciliaria de los empleados públicos, señalando un texto de Hermogeniano en el que se establece que el soldado tendrá su domicilio allí donde sirva en armas salvo que posea bienes en su patria:

D. 50.I.23』I (Hermogenianus, libro I. Iuris epitomarum): Miles ibi domicilium habere videtur, ubi moret, si nihil in patria possideat ${ }^{\text {To }}$.

Admitido que se trata de un texto genuino, como afirmara Tedeschi, de la mera lectura del mismo se observan las dificultades de su interpretación relativas a si nos encontramos ante un supuesto de domicilio legal y al papel que ocupa la posesión de bienes en la patria en la constitución del domicilio del soldado ${ }^{\text {II }}$.

A nuestro juicio, sin embargo, la pregunta esencial que debemos formularnos en primer lugar es cuáles fueron las razones que motivaron que a finales siglo III d. C. ${ }^{\mathrm{I}}$, y no con anterioridad, deviniera necesario regular el domicilio de los soldados; pregunta a la que trataremos de dar respuesta en estas líneas analizando la situación jurídica del miles en el marco de evolución que experimentó la composición y regulación del ejército romano en las distintas etapas de su historia.

Io Pauli Sententiae, I.Ia.7. GLÜCK, Ausführliche Erläuterung der Pandecten nach Hellfeld: ein Comentar, Vol. VI, cit., pág. 266; GASPARD, Recherches sur l'incolat, le droit de bourgeoisie et le domicile, cit., pág. I8; Chavanes, Du Domicile, cit., pág. 65; AnCelle, A., Du Domicile, Paris, I875, pág. 53; RouSSEL, Du domicile, en droit romain. De la formation des conventions, en droit international privé, cit., pág. 33; DE RUGGIERO, La patria nel diritto pubblico romano, cit., pág. I85; BRUGI, Istituzioni di Diritto Romano, cit., pág. 7I n. 24; SAVIGNY, Sistema de derecho romano actual, T. VI, cit., pág. I56; TEDESCHI, «Contributo allo studio del domicilio in Diritto romano», cit., pág. 23I; VISCONTI, A., «Note preliminari sul "domicilium” nelle fonti romane», en Scritti Ferrini, I, Milano, I939, pág. 43I; BURDESE, A., su voz «domicilio (Diritto romano)», en E.D., XIII, Milano, I964, pág. 838; LiEBS, D., Hermogenians Iuris Epitomae. Zum Stand der römischen Jurisprudenz im Zeitalter Diokletians, Göttingen, I964, pág. II8; SALGADO, «Contribución al estudio del "domicilium" en el Derecho romano», cit., pág. 503; VENDRAND-VOYER, J., Normes civiques et métier militaire à Rome sous le Principat, Clermont, I983, pág. I60 n. 3I; PLESCIA, «Conflict of Laws in the Roman Empire», cit., pág. 37; BACCARI, Cittadini popoli e comunione nella legislazione dei secoli IV-VI, cit., pág. IO2 n. 55; GUZMÁN BRITO, A., Derecho privado romano, Tomo I, Síntesis histórica del Derecho romano. Las acciones y el proceso. El derecho de las personas y de la familia. El derecho de las cosas y de su dominio, posesión, uso $y$ goce. El derecho de las obligaciones, Barcelona-Buenos Aires-México D.F.-Santiago de Chile, I997, pág. 287; LiCANDRO, Domicilium habere. Persona e territorio nella disciplina del domicilio romano, cit., pp. $357-358$.

II TEDESCHI, «Contributo allo studio del domicilio in diritto romano», cit., pág. 23I. Por su parte, LiCAndro, Domicilium habere. Persona e territorio nella disciplina del domicilio romano, cit., pág. 358, también reconoce que la dificultad del texto impide dar una solución.

${ }^{12}$ Aunque la doctrina más antigua tendía a aceptar como terminus post quem el año 365 d. C. (así, entre otros, RUdoRFF, A. F., Römische Rechtsgeschichte, I, 2 a edición, Leipzig, I857, pág. 276), en la actualidad es admitido que el Código Hermogeniano fue publicado en el año 295 d. C. Por todos, JöRS, P., s.v. «Codex Hermogenianus», en P.W.R.E., IV.I, Stuttgart, I900 (reimpresión de I992), cols. I64-I67; RoTONDI, G., «Studi sulle fonti del Codice Giustinianeo», en Scritti, I, Milano, I922, pp. iIo ss.; SCHERILlo, G., s.v. «Codex Hermogenianus», en N.N.D.I., III, Torino, I964, pág. 380; LIEBS, Hermogenians Iuris Epitomae. Zum Stand der römischen Jurisprudenz im Zeitalter Diokletians, cit., pág. 23; CENDERELli, A., Ricerche sul «Codex Hermogenianus», Milano, I965, pp. 7-Io; WolODKIEWICZ, W., «La prescription de l'action pénale à Rome», en R.H.D., I, I985, pág. Io y la copiosa bibliografía por ellos citada. Cfr. GAUDEMET, J., La formation du droit séculier et du droit de $l^{\prime}$ Eglise aux $I V^{e}$ et $V^{e}$ siècles, Paris, I957, pp. 42-43 que con una postura prácticamente aislada en la doctrina contemporánea se acoge a la teoría anterior. 


\section{Causas de la ausencia de regulación domiciliaria durante el período monárquico y republicano}

La ausencia de regulación domiciliaria en el ejército gentilicio de la primitiva monarquía, puede justificarse porque en esta milicia cívica, como indica Roldán Hervás, el ciudadano-soldado se limitaba a prestar auxilio a su patria en caso de conflicto y retornaba a su hogar cuando éste concluía puesto que las guerras, principalmente de carácter defensivo contra los pueblos vecinos, se resolvían en breves enfrentamientos ${ }^{\mathrm{I3}}$.

Las mismas razones pueden argumentar su ausencia en los primeros siglos del ejército ciudadano de base timocrática, instaurado según la tradición por Servio Tulio ${ }^{\mathrm{I}}$ dado que, como también señala Roldán Hervás, la guerra era condicionada, espacial y temporalmente a las necesidades del ciudadano-soldado para permitirle compaginar sus obligaciones militares con sus actividades económicas, fundamentalmente de carácter agrícola: «El ejército cívico supone un tipo de guerra rigurosamente limitada en el espacio para permitir al soldado trasladarse del campo de batalla al escenario de sus ocupaciones- y en el tiempo, dándole margen para compaginar ambas actividades», ya que la guerra se desarrollaba en los meses estivales, de marzo a octubre, coincidiendo generalmente con el período de obligado reposo en la agricultura ${ }^{15}$.

Sin embargo, la política expansionista romana trajo consigo una ampliación espacio-temporal de la guerra y, a partir de la Segunda Guerra Púnica, como apunta Milan, la obligación del soldado de permanecer durante años fuera de su domicilio en el lugar, cada vez más distante de aquél, donde su ejército estaba levantado en $\operatorname{armas}^{16}$.

No obstante, tampoco en este período se estableció una regulación domiciliaria. Es cierto que el soldado estaba obligado a permanecer junto a su ejército, bajo pena de ser condenado por un delito de deserción o transfuguismo ${ }^{17}$ pero, a pesar de tales delitos y de la

${ }^{13}$ Roldán Hervás, J. M., El ejército de la República romana, Madrid, I996, pág. Io; HeURGON, J., «La guerre romaine aux $4^{\mathrm{e}}{ }_{-3} \mathrm{e}$ siècles et la "Fides Romana”», en AA.VV., Problèmes de la guerre à Rome (J.P. Brisson dir.), Paris-La Haye, I969, pág. 23; MILAN, A., Le forze armate nella storia di Roma antica, Roma, I993, pp. 24 ss.; KEPPIE, L., The making of the roman army from Republic to Empire, Oklahoma, I998, pág. I4.

${ }^{14}$ Sobre la reforma de Servio Tulio, vid., entre otros, BRAND, C.E., Roman Military Law, London, I968, pp. 8 ss.; GABRA, E., Esercito e società nella tarda Repubblica romana, Firenze, I973, pp. 2 ss. y pp. 528 ss.; RoldÁN HERVÁs, J.M., Ejército y Sociedad en la Hispania romana, Granada, I989, pp. 20 ss.; idem, El ejército de la República romana, cit., pp. I2 ss. MILÁN, Le forze armate nella storia di Roma antica, cit., pp. II Ss. y pp. 2I2 ss.; KEPPIE, The making of the roman army from Republic to Empire, cit., pp. I5 SS.

${ }^{\text {I5 }}$ ROLDÁN HERVÁS, El ejército de la República romana, cit., pp. I5 ss.; BRISSON, J.P., «Les mutations de la deuxième guerre punique», en AA.VV., Problèmes de la guerre à Rome (J.P. Brisson dir.), Paris-La Haye, I969, pág. 39; LE BonNIEC, H., «Aspects religieux de la guerre à Rome», en AA.VV., Problèmes de la guerre à Rome (J.P. Brisson dir.), Paris-La Haye, I969 pp. IoI ss.; MiLAN, Le forze armate nella storia di Roma antica, cit., pp. 24 ss.

${ }^{16}$ MILAN, Le forze armate nella storia di Roma antica, cit., pág. 48; GABBA, Esercito e società nella tarda Repubblica romana, cit., pág. 48; idem, Per la storia dell'esercito romano in età imperiale, Bologna, I974, pág. 45; ROLDÁN HERVÁs, Ejército y Sociedad en la Hispania romana, cit., pp. 34 ss. y pp. 43 ss.; idem, El ejército de la República romana, cit., pp. 25 ss. y pp. 46 ss.; idem, Los hispanos en el ejército de época republicana, Salamanca, I993, pp. 34-35.

${ }^{17}$ Sobre tales delitos, ARANGIO-RUIZ, V., «Sul reato di diserzione in diritto romano», en Rivista di diritto e procedura penale, I0, I9I9, pp. I38-I47 (=Scritti di Diritto Romano, II, Camerino, I974, pp. II2); CARCAnI, M., Dei reati, delle pene e dei giudici militari presso i romani, Napoli, I98I, pp. 7I ss.; VALLEJO GIRVÉS, M., «Sobre la persecución y el castigo a los desertores en el ejército de Roma», en Polis. Revista de ideas y formas políticas de la Antigüedad clásica, 5, I993, pp. 24I-25I; idem, 
progresiva profesionalización del ejército ${ }^{18}$, hasta Augusto siguió primando el carácter ciudadano de su composición, situación que le permitía conservar la vinculación con su domicilio primitivo hasta el momento de su licenciamiento.

Prueba de ello es la introducción, a principios del siglo II a. C., de la Lex Porcia en virtud de la cual, si bien son conocidos sus incumplimientos y su escasa vigencia ${ }^{\mathrm{r}}$, en palabras de Rodríguez-Ennes "cuando un legionario en posesión del status civitatis cometía un delito por el que -caso de ser juzgado en Roma- debería concedérsele la provocatio, el comandante del ejército estaba obligado a enviar al reo ante los magistrados ordinarios de la civitas frente a cuya sentencia podía ejercitarse el ius provocationis"120.

Asimismo son significativas las referencias literarias que nos indican el retorno a su primitivo hogar de los soldados tras su licenciamiento. En efecto, la promesa del descanso, la vuelta a casa y la gloria en el futuro fueron los alicientes que Pulio Cornelio Escipión, el Africano Viejo, ofreció a sus soldados, según nos relata Apiano, para vencer a Aníbal $^{2 \mathrm{r}}$. Los contingentes militares de Q. Cecilio Materlo y Pompeyo, conforme al relato de Salustio, regresaron a Italia con sus jefes tras la victoria en las guerras sertorias y lo mismo hicieron los contingentes de César tras la batalla de Munda puesto que, como afirma Marín

«"Transfugae” en el ejército de Roma», en Hispania Antigua. Revista de Historia Antigua, XX, 1996, pp. 399-408; GIUFFRË, V., Letture e ricerche sulle «Res Militaris», I, Napoli, I996, pp. 83 ss.

I8 Ya en la época republicana asistimos a un proceso de proletarización del ejército como consecuencia de las reducciones del censo mínimo de la V clase, que será culminada por Gayo Mario en el año io7 a. C. cuando, junto al tradicional método del dilectus, recurrió al alistamiento de voluntarios non more maiorum neque ex classibus, sed uti cuisque lubido erat, capite censos plerosque para hacer frente a la guerra contra Yugurta (Salustio, Jugurtha, 86.2; Valerio Máximo, Facta et dicta memorabilia, 2.7.6). A partir de esta medida los soldados proletarios voluntarios, carentes de recursos económicos, consideraron el ejército como una profesión de duración indefinida y el mejor modo de recibir como recompensa una porción de tierra donde acabar su vida como pequeños propietarios agrícolas. Sobre esta evolución, BOTSFORD, G.W, The Roman Assemblies. From their origin to the end of the Republic, New York, I909 (reimpresión de I968), pp. 393 ss.; GÖHLER, J., Rom und Italiem. Die römische Bundesgenossenpolitik von den Anfängen bis zum Bundesgenossenkrieg, Breslau, I939, pp. I95 ss.; BRAND, Roman Military Law, cit., pp. II2-II3; HARMAND, J., «Le prolétariat dans la légion de Marius à la veille du second "bellum civile"», en AA.VV., Problèmes de la guerre à Rome (J.P. Brisson dir.), Paris-La Haye, I969, pp. 6i ss.; PARETTI, L., Storia di Roma, III, Torino, I953, pp. 446 ss.; GABBA, Esercito e società nella tarda Repubblica romana, cit., pp. 3-45, pp. 47 ss. y pp. 95 ss.; CRAWfORD, M., La República Romana (trad. esp. de A. Goldar), Madrid, I98I, pp. I26 ss.; MARÍN DÍAZ, M‥A., Emigración, colonización y municipalización en la Hispania romana, Granada, I988, pág. 49, pp. I69 ss., pp. I79-I80 y pp. I9I Ss.; MILAN, Le forze armate nella storia di Roma antica, cit., pp. 53 ss., pp. 70 ss. y pág. IOI; WulfF AlOnso, F., Romanos e Itálicos en la Baja República, Bruxelles, I99I, pp. 278 ss.; ROLDÁN HERVÁS, El ejército de la República romana, cit., pp. 26 ss. y pp. 47-59; idem, Los hispanos en el ejército de época republicana, cit., pp. 43 ss.; KEPPIE, The making of the roman army from Republic to Empire, cit., pp. 57 ss.

${ }^{19}$ VALLEJO GIRVÉS, «"Transfugae” en el ejército de Roma», cit., pág. 407, quien recoge ejemplos en los que se constata que esta ley no se respetó siempre ante los tránsfugas dado que generalmente eran tratados como «traidores» a Roma.

${ }^{20}$ RODRÍGUEZ-ENNES, L., «La “provocatio ad populum” como garantía fundamental del ciudadano romano frente al poder coercitivo del magistrado en la época republicana», en Studi in onore di Arnaldo Biscardi, IV, Milano, I983, pág. I08. Sobre esta ley, ZuMPT, A.W., Das kriminalrecht der römischen Republik, I, Berlin, I865 (reimpresión Aalen, I993), pág. I6; MoMMSEN, T., Le Droit pénal romain (traducción francesa de J. Duquesne), T. I, Paris, I907, pág. 34; MARTIN, J., «Die Provokation in der klassischen und späten Republik», en Hermes, 98, I970, pp. 87 ss.; GreENIDGE, A.H.J., The legal procedure of Cicero's time, Oxford, I90I (reimpresión New Jersey, I97I), pp. 32I Ss.

${ }^{21}$ APIANO, Africae, $4^{2}$. 
Díaz, Dión Casio nos indica que regresó a Italia dejando en la Ulterior un ejército poco considerable $e^{22}$.

Pero donde con mayor claridad se observa el mantenimiento del domicilio primitivo es en un pasaje de la Guerra Civil, recogido por Gabba, respecto a los licenciamientos que César realiza tras la batalla de Ilerda, en el que se utiliza dicho domicilio como ratio del licenciamiento, ya que se nos relata que fueron licenciados inmediatamente aquéllos legionarios que tenían el domicilio o que disponían de propiedades en Hispania:

«Paucis cum esset in utramque partem uerbis disputatum, res huc deducitur, ut ei, qui habeant domicilium aut possessionem in Hispania, statim, reliqui ad Varum flumen dimittantur» ${ }^{23}$.

Por tanto, conforme a este texto, los soldados conservaban el domicilio anterior al enrolamiento puesto que, tras la derrota, aquél fue uno de los criterios determinantes para concretar el tiempo y lugar de su licenciamiento ${ }^{24}$.

Esto no significa, obvio es, que todos los soldados regresaran a su primitivo domicilio tras su licenciamiento dado que los mismos podían decidir permanecer de forma estable en el lugar de destino, convirtiéndose en colonos de las tierras recién conquistadas que les eran entregadas como compensación, en virtud de distribuciones individuales o a través de colonias de veteranos fundadas para controlar o repoblar determinados

${ }^{22}$ SAlUSTIO, Historiae, 4.9; APIANO, Bella Civilia, I.I2I; DiÓN CASIO, Historiae Romanae, 45.IO.I. MARÍN DÍAZ, Emigración, colonización y municipalización en la Hispania republicana, cit., pág. I83.

${ }^{23}$ CÉSAR, Bellum Civile, r.86.3. Estos licenciados constituyeron una tercera parte de las tropas (César, Bellum Civile, I.87.4). GABBA, Esercito e società nella tarda Repubblica romana, cit., pp. 48I SS., para quien el término domicilium hace referencia a ciudadanos romanos que han puesto su domicilio en la provincia desarrollando una actividad económica, principalmente agrícola. Por contra, el término possessiones hace referencia al régimen propietario del suelo provincial. Para el autor, es seguro que los ciudadanos romanos tendrían en España propiedades fundiarias pero admite la posibilidad de que con dicho término César indicara a los no-ciudadanos (peregrini), esto es, a los indígenas hispanos propietarios de pequeñas explotaciones agrarias. En la misma línea, MARÍN DÍAZ, Emigración, colonización y municipalización en la Hispania republicana, cit., pp. I74 ss., sin negar la posible presencia de peregrini, considera probable que estos licenciados fueran ciudadanos romanos o itálicos domiciliados o con posesiones en Hispania; RoldÁn HERVÁs, Ejército y Sociedad en la Hispania romana, cit., pp. 72 SS., pp. I7I ss. y pp. 302 ss.; idem, Los hispanos en el ejército romano de época republicana, cit., pp. Ioo ss. y pp. IIo ss., para quién se trata de ciudadanos romanos de origen hispano o asentados en Hispania; LICANDRo, Domicilium habere. Persona e territorio nella disciplina del domicilio romano, cit., pág. 26 , pág. 89 , pág. I20, pág. I26 y pág. I 82 , que ve en este pasaje una diferencia entre la posesión de bienes y el domicilio. En nuestra opinión, consideramos también factible que entre estos licenciados se encontraran antiguos veteranos que al término de su servicio hubiesen preferido trasladar su domicilio a Hispania y desarrollar aquí su vida como colonos, los cuales, se habrían incorporado nuevamente a las armas ante las necesidades militares de la guerra hispánica ya que, como indica RoldÁn HeRVÁS, J.M., «"Legio Vernacula, iusta legio”», en Zephyrus, XXV, I974, pp. 457-47I, fue amplia la utilización de las reservas de ciudadanos romanos, nacidos en Hispania o asentados en ella, para completar o aumentar los efectivos de los ejércitos en lucha.

${ }^{24}$ En otros pasajes de Bellum civile se alude al regreso a sus casas de los soldados desertores. Vid., por ejemplo, I.I2.2, donde Termo, ante la llegada de César a Iguvio decide evacuar a sus cohortes y se da a la fuga: «militis in itinere ab eo discedunt ac domum reuertuntur»; I.I3.4, donde Atio Varo, ante la llegada de César a Áuximo, se da a la fuga pero es alcanzado por unos cuantos soldados de la vanguardia de César y entablan combate. Vario se ve desamparado de los suyos porque «nonnulla pars militum domum discedit; reliqui ad Caesarem perueniunt...». 
territorios ${ }^{25}$, o que ellos compraban personalmente con sus ahorros o arrebatan a los indígenas por la fuerza de las armas ${ }^{26}$.

Ciertamente Hispania es un claro ejemplo del traslado domiciliario de los soldados al lugar donde habían servido en armas, como constatan los asentamientos de itálicos procedentes de las filas del ejército, que sin constituir propiamente colonias, se atestiguan desde el siglo II a. C. Entre tales asentamientos se encuentra Italica donde Escipión tras la batalla de Ilipa instaló en el 206 a. C. a los muchos heridos del combate; Carteia, antigua fundación púnica que en el año I7I a. C. recibió un contingente de cuatro mil antiguos soldados romanos casados con indígenas, con su hijos, cuya condición de peregrinos -por tener una madre indígena- fue la causa de que a su ruego se llevara a cabo este asentamiento, manumitiéndolos y dándoles tierras; Corduba fundada en el año I52 a. C, según Estrabón con ciudadanos romanos e indígenas selectos entre los que se encontraban, respectivamente, antiguos legionarios y auxiliares; o Valentia fundada en el i38 a. C. que debió recibir en el curso de dicho siglo contingentes de soldados licenciados ${ }^{27}$.

Las razones de dicha permanencia son claramente sintetizadas por Roldán Hervás: "tanto para el soldado legionario romano, como, aún más, para el aliado itálico, obligado a permanecer en servicio continuado durante un largo período -como mínimo seis años- en las lejanas provincias occidentales, y ante la perspectiva del regreso a Italia, abandonando sus campos, si es que los tenía, y constreñido a competir con el creciente latifundio, es completamente lógico que la alternativa de regreso fuera desechada frente a la posibilidad

${ }^{25}$ La finalidad militar de la colonización nos es atestiguada por Cicerón, De lege agraria, 2.73, donde califica a la colonia de propugnacula imperii. Al respecto, GABBA, Esercito e società nella tarda Repubblica romana, cit., pág. 35I. Por su parte, CASTELLO, C., «Il cosidetto ius migrandi dei latini a Roma. Ricerche in tema di concessione e accertamento degli status civitatis et familiae dal 338 al 95 av. C.», en B.I.D.R., 5I-52, I958, pp. 22I-222, señala el carácter defensivo de las mismas. Sobre ésta y otras razones de la política colonial, SAUMAGNE, CH., Le droit latine et les cités romaines sous l'Empire, Sirey, I965, pp. 49 ss.; LURASCHI, G., Foedus Ius Latii Civitas. Aspetti costituzionali della romanizzazione in Transpadana, Padova, I979, pp. 7 ss. y pp. 6o-6I; RICCOBONO JR., S.., «Le "civitates" nell'unità dell'impero romano: autonomie locali e politica del territorio», en La città antica come fatto di cultura. Atti del Convegno di Como e Bellagio 16/10 giugno 1979, Como, I983, pág. 219; SPAGNUOlO Vigorita, T., Città e Impero. Un seminario sul pluralismo cittadino nell'Impero romano, Napoli, ı996, pág. 53 y pp. 83 ss.

${ }^{26}$ La práctica de que los soldados veteranos recibieran tierras en el lugar donde habían servido no era un hecho generalizado hasta Sila. No obstante, cuando este reparto no sucedía, los propios soldados podían adquirirlas mediante su compra, alquiler o a través de las armas. Así, por ejemplo, Tácito (Annales, I4.3I), nos relata el odio que Prasutago, rey de los icenos, tenía contra los veteranos que llevados a la colonia de Camuloduno, los echaban de sus casas y los expulsaban de sus campos llamándoles cautivos y esclavos. Al respecto, GABBA, Esercito e società nella tarda Repubblica romana, cit., pp. 40-4I, pp. IOO ss. y pp. II7 ss.; ROLDÁN HERVÁS, Ejército y Sociedad en la Hispania romana, cit., pp. 34 SS. y pp. I56 ss.; MARÍN DÍAZ, Emigración, colonización y municipalización en la Hispania republicana, cit., pág. I7I; LE BOHEC, Y., L'Armée romaine sous le Haut-Empire, I990, pág. 240 y pág. 250; CAMPBELL, B., The roman army 31 BC-AD 337, London-New York, I994, págas. 22 I-222.

${ }^{27}$ Sobre estos y otros asentamientos, así como sobre la emigración y el asentamiento militar en la época republicana e imperial, vid., GABBA, Esercito e società nella tarda Repubblica romana, cit., pág. 54, pp. I05-IO6, pp. 289 ss. y pp. 49I ss.; SAUMAGNE, Le droit latine et les cités romaines sous l'Empire, cit., pp. 49 ss.; GARNSEY, P., Social status and legal privilege in the roman Empire, Oxford, I970, pp. 249 ss.; ROLDÁN HERVÁs, Ejército y Sociedad en la Hispania romana, cit., pág. 74, pp. IIO-III y pp. I52 ss.; idem, Los hispanos en el ejército romano de época republicana, cit., pp. 84-85, pág. 94 y pág. 97; MARÍN DíAZ, Emigración, colonización y municipalización en la Hispania republicana, cit., pp. 47 ss., pp. 82 ss. y pp. II8 ss.; KEPPIE, L., Colonisation and veteran settlement in Italy 47-14 B.C., London, I983, pp. 23 ss.; idem, The making of the roman army from Republic to Empire, cit., pág. I82; LE BOHEC, L'Armée romaine sou le Haut-Empire, cit., pp. 239-249; CAMPBELL, The roman army 31 BC-AD 337, cit., pp. 210 ss.; AlSTON, R., Soldier and Society in roman Egypt, London-New York, I995, pp. 39 ss.; WebSTER, G., The roman imperial army, London, I996, pp. 277 ss.; RODRÍGUEZ-ENNES, L., Gallaecia: Romanización y ordenación del territorio, Madrid, 2004, pp. 58-60. 
de establecimiento en unas nuevas tierras que ya no le eran extrañas y con enormes ventajas para rehacer su vida como civil, donde, por otro lado, no es improbable que hubiese ya atado lazos de tipo familiar"128.

En consecuencia, de los pasajes citados se observa la primacía del carácter cívico en la composición del ejército y que el soldado conservaba su vinculación con el domicilio primitivo hasta su reintegración a la vida civil, momento en el cual, o bien podía regresar, o bien permanecer de modo estable en el lugar donde había cumplido servicio.

\section{Configuración del domicilio necesario durante el Imperio y hasta Justiniano: Análisis de la posesión de bienes en la patria}

Con Augusto, en palabras de Milan, sin abolir el principio de conscripción obligatoria, se culmina el proceso de profesionalización del ejército al fundar, bajo una rígida regulación, el servicio voluntario profesional y transformar el ejército en guarnición permanente de la que él era el comandante supremo ${ }^{29}$.

Podría pensarse, por tanto, que esta profesionalización comportó una obligación domiciliaria del soldado en el lugar de destino, sancionada por el delito de deserción y el delito de transfuguismo, si el soldado acababa por pasarse al enemigo, sobre todo, si se tiene en cuenta, como recoge Giuffrè, el rígido criterio de la común denominada disciplina Augusti referida por Paterno y recogida por Emilio Macer, en virtud del cual, los que estaban al frente de un cuerpo armado debían dar muy parcamente licencias:

\footnotetext{
D. 49.I6.I2』i (Marcer, libro I. de re militari): ... debere eum, qui se meminerit armato praeesse, parcissime commeatum dare ${ }^{30}$.
}

Sin embargo, tales delitos, como ocurría en el período precedente, no tipificaban el incumplimiento de una obligación domiciliaria, sino faltas máximas a la disciplina militar,

\footnotetext{
${ }^{28}$ ROLDÁn HERVÁS, Ejército y Sociedad en la Hispania romana, cit., p. 74. En el mismo sentido GABBA, Esercito e società nella tarda Repubblica romana, cit., pp. I05-I06 y pp. 289 ss.: «Molti militari finivano, dopo lunghi anni di servizio, per stabilirsi nella provincia ove avevano militato e ove si erano creati o amicizie o addirittura famiglie»; MARÍN DÍAZ, Emigración, colonización y municipalización en la Hispania republicana, cit., pp. 47 ss., afirma que la presencia ininterrumpida de contingentes armados en la Península se atestigua desde el año 2I8 a. C., muchos de los cuales, sobre todo aliados itálicos, no volverían a Italia tras su licenciamiento sino que se asentarían de una manera estable en Hispania convirtiéndose en agricultores. Asimismo, la autora pone de manifiesto que el flujo migratorio que se proyecta a Hispania en el siglo II a. C. tuvo un doble componente: los contingentes militares licenciados que prefirieron permanecer en la Península antes de regresar a Italia, sobre la que se proyectó de forma creciente, a partir de las grandes guerras de conquista del siglo II a. C., una profunda crisis agraria; y los componentes civiles que tuvieron como objeto la explotación de los recursos naturales, especialmente mineros; KEPPIE, Colonisation and veteran settlement in Italy 47-14 B.C., cit., pp. IOI ss.

${ }^{29}$ MILAN, Le forze armate nella storia di Roma antica, cit., pp. III Ss.; BRAND, Roman Military Law, cit., pp. II7 ss.; GABBA, Per la storia dell'esercito romano in età imperiale, cit., pp. 45 Ss.; MONTERO, S.BRAVO, G.-MARTÍNEZ-PINA, J., El Imperio romano, Madrid, I982, pp. 30 ss.; ROLDÁN HERVÁS, Ejército y Sociedad en la Hispania romana, cit., pp. 76 ss., pp. I22 ss. y pp. 243 ss.; idem, El ejército de la República romana, cit., pp. 6I ss.; LE BOHEC, L'Armée romaine sous le Haut-Empire, cit., pp. I94 ss. (= The imperial roman army, London, I994, pp. 82 ss.); KEPPIE, The making of the roman army from Republic to Empire, cit., pp. 145 ss.

${ }^{30}$ GIUfFRÈ, V., Letture e ricerche sulla «Res militaris», II, Napoli, I996, pp. 294-295 y pág. 4I4 n. 77; DAVIES, R.W., «The daily life of the roman soldier», en A.N.R.W., I.2, I974, pág. 333 (-BREEZE, D.MAXFIEL, V. (eds.), Service in the roman Army, Durham, I989, pág. 67).
} 
a su juramento militar (sacramentum) que, como indica Vallejo Girvés, dado el grave perjuicio económico, social y político que podían causar al ejército, en muchas ocasiones eran consideradas como "un delito de carácter de Estado, esto es, de traición" ${ }^{135}$.

Por otro lado, en favor de un domicilio legal de los soldados, se podría aducir un pasaje de Suetonio, en el que se nos indica que Nerón fundó una colonia en Ancio asignando a la misma a los veteranos de la guardia pretoria y completando su número, por traslado de su domicilio, con los más ricos primipilarios:

Suetonio, De vita duodecim Caesarum. Nero, 9: "Antium coloniam deduxit ascriptis ueteranis e praetorio additisque per domicilii translationem ditissimis primipilarium".

A juicio de Tedeschi, resulta curioso que sólo respecto a los "ditissimi primipilarium" se hable de traslado de domicilio, pero niega que se trate de un domicilio legal, siendo las posibles coincidencias con D. 50.I.23『I fortuitas y explicables de otro modo $^{32}$, opinión que compartimos puesto que, como se desprende del propio pasaje, Suetonio no habla de soldados sino de veteranos y su traslado de domicilio no presenta un régimen domiciliario particular al del resto de ciudadanos que, como señala Galli, en virtud de una disposición imperial, podían ser destinados a constituir una nueva ciudad o a incrementar demográficamente una ya existente, perdiendo su ciudadanía local y la tribu originaria para adquirir las de la nueva ciudad ${ }^{33}$.

Además, la vinculación del miles con su primitivo domicilio se constata en los problemas de reclutamiento, señalados por Gabba, motivados por el deseo de los soldados

\footnotetext{
${ }^{31}$ VALLEJO GIRVÉS, «Sobre la persecución y el castigo a los desertores en el ejército de Roma», cit., pp. 24I-242; idem, “"Transfugae” en el ejército de Roma», cit., pág. 404. En el mismo sentido, GARNSEY, Social status and legal privilege in the roman Empire, cit., pág. I42; JONES, H., «L'ordre pénal de la Rome antique: contexture et limites», en Latomus, 4.5I, I992, pág. 756. Sobre los delitos militares, REIN, W., Das Kriminalrecht der Römer von Romulus bis auf Justinian, Lepizig I844 (reimpresión Aalen, I962) pp. 698 ss.; CognAT, R., su voz «militum poenae», en D.S., III.2, Paris, I904, pp. I895 ss.; MOMMSEN, T., Le Droit pénal romain, (traducción francesa de J. Duquesne), Paris, I907, T. II, pp. 262 ss.; FERRUCCIO FALCHI, G., Diritto penale romano. II singoli reati, Padova, I932, pp. 248 ss.; CARCANI, Dei reati, delle pene e dei giudici militari presso i romani, cit., passim; CARNAZZARAMETTA, G., Studio sul diritto penale dei romani, Roma, I972 (edición anastática invariada de la edición de Messina I883), pp. 220 ss.; MENTXACA, R., «De la penalización en Derecho romano de la tentativa de suicidio de los militares y la permanencia histórica de su regulación», en VII Congreso Internacional y X Iberoamericano de Derecho Romano. El Derecho penal: De Roma al Derecho actual, Madrid, 2005, pp. 38I-400. Sobre el sacramentum, VENDRAND-VOYER, «Origine et développement du “droit militaire” romain», cit., pp. 259 ss.; BRAND, Roman Military Law, cit., pág. 47 y pp. 9I ss.; MILAN, Le forze armate nella storia di Roma antica, cit., pág. Io8; LE BONNIEC, «Aspects religieux de la guerre à Rome», cit., pp. I05 Ss.; WATSON, G.R., The roman soldier, New York, I995, pp. 44 Ss.

${ }^{32}$ TEDESCHI, «Contributo allo studio del domicilio in Diritto romano», cit., pág. 23I. Sobre este pasaje, LE BOHEC, L'Armée romaine sous le Haut-Empire, cit., pág. 240 n. 20 (- The imperial roman army, cit., pág. 225 n. 20), para quien este relato es un ejemplo de que los veteranos podían regresar a su patria o instalarse lejos de ella, junto al lugar en el que habían servido; CAMPBELL, The roman army $31 B C-A D$ 337, pág. 2I5.

${ }^{33}$ GALLI, F., «Cambio di tribu 'per domicilii traslationem' nelle regioni augustee VI, VII e VIII», en Quaderni Urbinati di Cultura Classica, I8, I974, pp. I33-I34,. El autor recoge así el caso de los veteranos pertenecientes a las legiones VIII Augusta y XV Apollinaris deducidos por el emperador Claudio a Savaria, adscrita a la tribu Claudia, algunos de los cuales se establecieron definitivamente en Savaria y otros retornaron a Carnuntum, donde habían servido. Lo mismo pasó con Ancio, como nos relata Tácito (Annales, I4.27) que, si bien afirma que Tarento y Ancio fueron pobladas con legionarios veteranos de distintas unidades desconocidos entre sí, sin hacer referencia a los pretorianos, nos indica a su vez que los mismos abandonaban sus casas y acababan dispersándose por las provincias en las que habían cumplido su servicio.
} 
de no alejarse de la propia sede. Como afirma el autor, la incapacidad de mantener el principio de que en las legiones pudieran entrar sólo ciudadanos de origen itálico, ante la dificultad de encontrar elementos itálicos dispuestos a abandonar los propios campos o la propia ocupación y andar a servir en las lejanas fronteras, determinó la necesidad de alargar el área de reclutamiento a las provincias de tal forma que, al inicio del siglo II d. C., las áreas de reclutamiento vinieron a coincidir con aquéllas de estacionamiento de las legiones y con el otorgamiento de la ciudadanía a los peregrinos en el momento de su enrolamiento ${ }^{34}$.

Se establecen así las premisas para la futura "barbarización" del ejército y se permite a los soldados mantener su primitivo domicilio, haciéndolo coincidir con el lugar de levantamiento en armas.

Pero, incluso en los supuestos en que tal coincidencia no fuera posible, la conservación del primitivo domicilio se deduce de un rescripto del año 224, recogido por Hernández-Gil, en el que el emperador Alejandro contesta al veterano Venuleyo que el tiempo de una expedición no produce la longi temporis praescriptio contra las peticiones que justamente le competieron:

C. I. 7.35.I (Imp. Alexander A. Venuleio, veterano): Tempus expeditionis adversur petitiones, si quae competiisse iuste probari possunt, praescriptionem non parit $^{35}$.

Del mismo modo, dicha vinculación se desprende de la restitutio in intregum que, como indica De Martino, se concede a los soldados per absentia rei publicae causa ${ }^{36}$. A este respecto, en el año 223 d. C. el emperador Alejandro, dirigiéndose al militar Flavio Aristodemo, le indica que está permitido reivindicar la posesión de los bienes que durante el tiempo de la milicia fueron poseídos por otro:

C. I. 2.5I(50).3 (Imp. Alexander A. Flavio Aristodemo, militi): Quod tempore militiae de bonis alicuius possessum ab aliquo est, posteaquam is reipublicae causa abesse desiit, intra annum utilem, amota praescriptione temporis medii, possessionem vindicare permissum est; ultra autem ius possessoris laedere contra eum institutum non oportet.

Y, posteriormente, Valeriano y Galieno, dirigiéndose al centurión Germano, afirman que si ocupado en el servicio los herederos de su acreedor vendían las posesiones a

${ }^{34}$ GABBA, Esercito e società nella tarda Repubblica romana, cit., pág. 95; idem, Per la storia dell'esercito romano in età imperiale, cit., pág. 46; DE MARTINO, F., Storia della Costituzione Romana, $2^{\mathrm{a}}$ edición, Napoli, I972, vol. IV, pp. 936 ss. y pág. 947; DEMOUGEOT, E., «Le “conubium” et la citoyenneté coonféreé aux soldats barbares du Bas-Empire», en Sodalitas. Scritti in onore di Antonio Guarino, IV, Napoli, I984, pp. I633 ss.; LE BoHEC, L'Armée romaine sous le Haut-Empire, cit., pp. 72 ss. y pp. 249-250 (- The imperial roman army, cit., pp. 68 ss.), califica al ejército como «máquina de fabricar ciudadanos romanos»; MILAN, Le forze armate nella storia di Roma antica, cit., pág. II3 y pp. I53 ss.; CAMPBELL, The roman army 31 BC-AD 337, cit., pp. 9 ss.; WATSON, The roman soldier, cit., pp. I37 SS.; WEBSTER, The roman imperial army, cit., pp. IO7 ss.; KEPPIE, The making of the roman army from Republic to Empire, cit., pág. I48 y pp. I80 ss.; RICHARDOT, P., La fin de l'armée romaine (284476), Paris, I998, pp. 62 ss.

${ }^{35}$ HernándeZ-Gil, A., El testamento militar (En torno a un sistema hereditario miliar romano), Madrid, I946, pág. II2; BRUGI, Istituzioni di Diritto Romano, cit., pág. 65; AmElotTI, M., La prescrizione delle azioni in Diritto romano, Milano, I958, pp. I9I-I92.

${ }^{36}$ DE MARTINO, Storia della Costituzione Romana, IV, cit., pág. 944; AMELOTTI, La prescrizione delle azioni in Diritto romano, cit., pág. I6 n. 38, pp. 95-96 y pág. I92; ALSTON, Soldier and Society in roman Egypt, cit., pp. 57 ss. 
su favor obligadas, él podría impetrar la restitución por entero y anular la venta para recobrar sus posesiones:

C. I. 2.5I(50).6 (Impp. Valerianus et Gallienus AA. Germano, Centurioni): Si, quum militaribus laboribus operam dares, creditoris tui heredes possessiones sibi obligatas distraxerunt, poteris adito praeside provinciae in integrum re titutionem impetrare, retractataque venditione recipies possessiones, oblato ante debito vel pretio, si minus debito fuisset.

Igualmente, se observa en la suspensión temporal de exenciones a los munera locales, señala por Sirks, durante el tiempo en que el soldado, en virtud de un permiso, estuviera en casa dado que, durante el mismo, no se consideraba que estuviera ausente rei publica causa. En efecto, conforme a un pasaje de Ulpiano, los soldados no podían ser llamados a los cargos locales mientras estaban en el campamento prestando su servicio:

\title{
D. 50.4.3』I (Ulpianus, libro II. Opinionum): His, qui castris operam per militiam dant, nullum municipale munus iniungi potest ${ }^{37}$.
}

Tampoco mientras iban y regresaban al mismo o mientras iban y regresaban a su casa con licencia, dado que conforme a un texto de Paulo, durante este tiempo también se consideraba que estaban ausentes rei publicae causa:

\begin{abstract}
D. 4.6.35『9 (Paulus, libro III. ad legem Iuliam et Papiam): Et dum eat in castra et redeat, Reipublicae causa abest; quod et eundum sit in castra militaturo, et redeundum. Vivianus scribit Proculum respondisse, militem, qui commeatu absit, dum domum vadit aut redit, Reipublicae causa abesse; dum domi sit, non abesse $^{38}$.
\end{abstract}

Pero, como se observa en la parte final del pasaje, en la que Paulo recoge la respuesta de Próculo, el soldado no se consideraba ausente rei publicae causa durante el tiempo que estaba en casa en virtud de un permiso. $\mathrm{Y}$ en el mismo sentido se pronuncia Javoleno:

\author{
D. 4.6.34 (Iavolenus, libro XV. ex Cassio): Miles commeatu accepto si \\ domo sua est, Reipublicae causa abesse non videtur ${ }^{39}$.
}

Por tanto, durante este tiempo, a juicio de Sirks, la inmunidad de los soldados era temporalmente suspendida y los mismos podían ser llamados a los cargos locales, al igual que ocurría cuando estaban ausentes por más tiempo del de su licencia o en otra forma que la dada en la misma, como apunta Ulpiano:

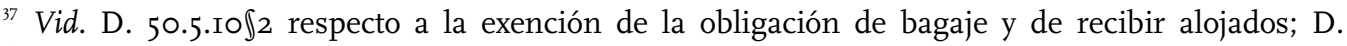
50.6.7, donde se enumera el personal militar exento de los graviora munera. SIRKS, A.J.B., «Munera publica and exemptions (vacatio, excusatio and inmunitas)», en Studies in Roman Law and Legal History in Honour of R. D'Abadal, I989, pág. 93 y pág. 95. Al respecto, DE RUGGIERO, La patria nel diritto pubblico romano, cit., pág. 64; SANTAlUCIA, B., I «libri opinionum» di Ulpiano, Milano, I97I, vol. I, pág. 84 n. 2I, pp. II3 ss. y pág. I60, vol. II, cit., pp. IO9-IIO, pág. II8 n. 82, pág. I49 y pág. I56; CAMPBELL, The roman army $31 B C-A D$ 337, cit., pág. 30; WATSON, The roman soldier, cit., pp. 75 ss.

${ }^{38}$ SIRKS, «Munera publica and exemptions (vacatio, excusatio and inmunitas)», cit., pág. 95; ALSTON, Soldier and Society in roman Egypt, cit., pág. 57; GIUFFRÈ, Letture e ricerche sulla «Res Militaris» II, cit., pág. 247 n. 38.

39 SIRKS, «Munera publica and exemptions (vacatio, excusatio and inmunitas)», cit., pág. 95; ALSTON, Soldier and Society in roman Egypt, cit., pág. 57; GIUFFrÈ, Letture e ricerche sulla «Res Militaris», II, cit., pág. 247 n. 38. 
D. 50.I.2 $₫ 6$ (Ulpianus, libro I. Disputationum): Is, qui ultra commeatum abest, vel ultra formam commeatui datam, ad munera vocari potest ${ }^{40}$.

En consecuencia, el análisis de estos textos nos permite afirmar que el soldado conservaba su primitivo domicilio, bien porque el mismo coincidía con la zona de reclutamiento, bien porque, a falta de tal coincidencia, teniendo en cuenta que el soldado podían estar durante largo tiempo alejado del mismo, se arbitraban una serie de disposiciones tendentes a garantizar y proteger sus intereses.

No obstante, los problemas relativos al régimen domiciliario se incrementaron ante la creciente necesidad, constatada por Gabba, de un ejército de maniobra móvil y la incomodidad de los tropas, reclutadas localmente, de dejar indefensa la propia casa para ir a combatir a otras zonas alejadas del Imperio, situación que se agravó cuando Septimio Severo reconoció los matrimonios de los soldados puesto que, ese reconocimiento, reforzó los vínculos entre los soldados y la zona de estacionamiento y provocó una progresiva compenetración entre el ejército y la vida civil que incrementó el recelo de los soldados por alejarse $^{4 \mathrm{I}}$.

Esta situación comportó una extensión del componente bárbaro en las filas del ejército, a través de la formación de tropas auxiliares orientales, reclutadas en sus zonas de origen, y la creciente introducción en el ejército de elementos góticos y germánicos a partir del siglo III d. C. derogando, respecto a los mismos, el principio de enrolamiento local en la zona de estacionamiento en la medida en que, como indica Gabba, podían haber sido admitidos en el suelo romano para repoblar determinadas zonas depresivas o ser reclutados "más allá de los confines" de tal forma que, en el siglo IV d. C., el fenómeno de la "barbarización" era ya irreversible y la proporción de bárbaros, sobre todo germánicos, fue creciendo tanto en el ejército de frontera como en el de maniobra, ante la insuficiencia de voluntarios ciudadanos, así como de la conscripción forzosa a través del sistema hereditario y de la exacción fiscal (praebitio tironum) ${ }^{42}$.

Es en el marco de estas circunstancias y en el contexto de guerra permanente en el que, como indica Richardot ${ }^{43}$, el Imperio vive acosado por las invasiones exteriores y las

${ }^{40}$ SIRKS, «Munera publica and exemptions (vacatio, excusatio and inmunitas)», cit., pág. 95 .

${ }^{4 \mathrm{I}}$ GABBA, Per la storia dell'esercito romano in età imperiale, cit., pp. 54 Ss. Al respecto, MISPOULET, J.B., Études d'Institutions Romaines, Paris, I887, pp. 230 ss.; PflAUM, H.G., «Forces et faiblesses de l'armée romaine du Haut-Empire», en AA.VV., Problèmes de la guerre à Rome (J.P. Brisson dir.), ParisLa Haye, I969, pp. 86 ss.; DE MARTINO, Storia della Costituzione Romana, IV, cit., pág. 940; CAMPBELL, The roman army 31 BC-AD 337, cit., pp. I40 ss. y pp. I5I-I52.

${ }^{22}$ GABBA, Per la storia dell'esercito romano in età imperiale, cit., pp. 54 ss.; GAUDEMET, J., «L'étranger au Bas-Empire (I)», en AA.VV., L'Étranger, I, Bruxelles, I985, pp. 209 ss.; PFLAUM, «Forces et faiblesses de l'armée romaine du Haut-Empire», cit., pp. 96 ss.; RolDÁn HERVÁs, Ejército y Sociedad en la Hispania romana, cit., pág. 78; DEMOUGEOT, «Le "conubium” et la citoyenneté conféreé aux soldats barbares du Bas-Empire», cit., pp. I633 ss.; JONES, A.H.M., The Later Roman Empire 284-602: a social, economic, and administrative survey, I, Oxford, I990, pp. 6II ss.; LE BOHEC, L'Armée romaine sous le Haut-Empire, cit., pp. 72 ss.; MILAN, Le forze armate nella storia di Roma antica, cit., pp. I75 Ss.; GIUFFRÈ, Letture e ricerche sulla «Res militaris», II, cit., pp. 324 SS.; BRULET, R., «Les transformations du Bas-Empire», en REDDÉ, M. (Dir.), L'armée romaine en Gaule, Paris, I996, pp. 262 ss.; ELTON, H., Warfare in roman Europe AD 350-425, Oxford, I996, pp. I28 ss.; RICHARDOT, La fin de l'armée romaine (28-476), cit., pp. $267 \mathrm{ss}$.

${ }^{43}$ RiCHARDOT, La fin de l'armée romaine (284-476), cit., pág. I5; MONTERO-BRAVO-MARTínEZPINNA, El Imperio romano, cit., pág. 329, afirman que ante las dramáticas circunstancias por las que atraviesa el Imperio a partir del siglo III d. C., continuamente amenazado por las invasiones 
propias rebeliones militares internas que justifican la primacía del ejército en este momento, donde debemos ubicar las palabras de Hermogeniano en virtud de las cuales, "el soldado tenía su domicilio en el lugar donde servía en armas salvo que poseyera bienes en su patria":

D. 50.I.23』I (Hermogenianus, libro I. Iuris epitomarum): Miles ibi domicilium habere videtur, ubi moret, si nihil in patria possideat.

Convenimos, en consecuencia con Visconti ${ }^{44}$, en que su fundamento se corresponde con la importancia del elemento militar en esta época y con la necesidad de regular una situación bastante frecuente, ante el reclutamiento de las tropas de origen bárbaro y el declive del criterio de reclutamiento en la propia zona de estacionamiento en la que el soldado servía en armas, bien en el ejército de maniobras, bien en un destino alejado de su primitivo domicilio, estableciéndose la presunción de que sólo continuaba vinculado al mismo si poseía bienes en su patria.

Esta posesión no creemos que deviniera en elemento constitutivo del domicilio del soldado sino que, como indica Tedeschi, era "un indicio de una relación de fijación del soldado respecto a aquel lugar, el cual permanecía como punto de apoyo en su vida"45. Por este motivo, no compartimos la opinión del autor relativa a atribuir un significado restrictivo al término patria como lugar de origen sino que, a nuestro juicio, con el mismo Hermogeniano hacía referencia al lugar de donde había salido el soldado para prestar sus servicios militares y en el que tenía establecido su domicilio, el cual, si bien coincidía normalmente con el lugar de su origo, en ocasiones, también podía ser distinto al mismo si el soldado era un incola, es decir, habitante de una ciudad diferente a la de su origo, dado que no encontramos ninguna razón para que la regla descrita no pudiera ser aplicada también en este supuesto ${ }^{46}$.

El carácter de mero indicio del centro de los intereses y negocios ha sido también defendido por Carnelutti, para quien, si aquél hubiera sido realmente la base del domicilio,

exteriores y por las frecuentes usurpaciones, el ejército adquiere una importancia que lejos estaba de conseguir durante el Principado.

44 VISCONTI, «Note preliminari sul “domicilium” nelle fonti romane», cit., pág. 43I. Cfr. VENDRAND-VOYER, Normes civiques et métier militaire à Rome sous le Principat, cit., pág. IGo, relaciona esta disposición con el intento de evitar una aplicación abusiva del ius domum revocandi que era concedido a los soldados.

45 TEDESCHI, «Contributo allo studio del domicilio in Diritto romano», cit., pág. 23I. Por su parte, LiCANDRO, Domicilium habere. Persona e territorio nella disciplina del domicilio romano, cit., pág. 358, no se atreve a dar una solución limitándose a opinar que la subordinación del domicilio a la posesión de bienes en la patria no es coherente con el «se instructus» en un lugar que constituye en general criterio para individualizar el domicilio de una persona. No obstante, deja abierta la posibilidad y señala la ausencia de referencia al elemento intencional así como a la fuerza que parece tener el particular vínculo con la patria. En cualquier caso, el autor considera que no es posible admitir una dualidad de domicilio a favor del soldado.

${ }^{46}$ LICANDRO, Domicilium habere. Persona e territorio nella disciplina del domicilio romano, cit., pág. 358 n. I52, ya consideraba que si el militar podía tener algún vínculo en un lugar distinto era donde tuviese propiedades inmobiliarias, no quedándole claro porqué dicho principio no debía valer cuando dichas propiedades se encontrasen en un lugar diverso al de la patria entendida como lugar de origen. Sobre los significados del término patria, DE RUGGIERO, La patria nel diritto pubblico romano, cit., pp. I2 ss; VON LÜBTOW, U., Das Römische Volk, Frankfurt am Mein, I955, pág. 648; GAUDEMET, J., «L'étranger dans le monde romain», en Studii Clasice, 7, I965, pág. 46 (= Étude de droit romain, vol. III, Camerino, I979, pág. 430); BONJOUR, M., Terre natale. Études sur le patriotisme romain, Paris, I975, pp. 4I ss. 
ninguna dificultad hubiera existido para reconocer que la morada en el lugar de la milicia no "eliminaba el domicilio primitivo"47.

En consecuencia, la posesión de bienes en la patria, entendida en el sentido expuesto, sólo servía como indicio o presunción de que el soldado conservaba su domicilio primitivo y sólo cuando dicha presunción se destruía, el Derecho público le atribuía un domicilio en el lugar donde servía en armas.

A esta conclusión llega Chavanes, sobre el criterio de la destinatio animi del soldado al afirmar que, si nada le vinculaba al lugar del que había salido para prestar sus servicios militares, "su intención debía descansar en el lugar donde él permanecía para combatir, donde él recibía la paga" ${ }^{148}$.

A similar conclusión llega Ancelle, aunque desde el punto de vista del centro de sus intereses, para quien el soldado, cuando no poseía bienes en su patria, tenía su domicilio en el lugar donde le retenía el servicio puesto que, no teniendo ningún interés en aquel lugar, se presume que el centro de sus negocios o fortuna se encontraba donde él servía en armas. Por el contrario, si poseía bienes en su patria, allí conservaba su domicilio primitivo ${ }^{49}$.

Y, de acuerdo con la opinión de Bruguière, el domicilio en el lugar de armas no existiría de facto mas que para los soldados que no tuvieran ya $u_{n o}^{50}$.

Por tanto, aunque a través de distintos criterios, el análisis de estas posturas nos conduce a afirmar que, en relación con el soldado, sólo cabe hablar de domicilio legal bajo ciertas reservas dado que, a diferencia de lo que ocurría con el domicilio de los senadores o decuriones, en este caso el Derecho público no eliminaba la libre voluntas del soldado, sino que se limitaba a atribuirle un domicilio en el lugar donde servía en armas cuando se destruía la presunción de que conservaba el domicilio primitivo ${ }^{51}$.

Esta interpretación, pudo servir a su vez al Derecho público para reforzar el vínculo del soldado con su cuerpo militar y con su lugar de destino, al limitar sus solicitudes de ausencias a los supuestos en que el soldado tuviera tales bienes. En efecto, las abusivas solicitudes de commeatus, a través de las cuales los soldados, con el pretexto de regresar a sus domicilios para atender sus propios intereses, se ausentaban masivamente de sus zonas de destino, llevará a Constantino, como señala Giuffrè, incluso a prohibir en el año 323 d. C. que los praepositi, decuriones y tribuni de las cohortes de cualquier tipo concedieran a los militares licencia para alejarse de los campamentos y de sus puestos, bajo amenaza de graves sanciones que podían alcanzar incluso la pena capital:

${ }^{47}$ CARneluTti, F., «Intorno ai concetti di domicilio, resindenza e dimora», en A.G., I905, pp. 402 ss. Sobre el carácter subsidiario del centro de intereses LóPEZ HUGUET, Ma.L., «Un estudio sobre la configuración jurídica del término domicilium en Derecho romano», en R.G.D.R. (http://www.iustel.com) 8, junio, 2007, pp. I ss.

${ }^{48}$ Chavanes, Du Domicile, cit., pág. 65.

${ }^{49}$ ANCELle, Du Domicile, cit., pág. 53.

50 Bruguière, M.B., «Le domicile dans les droits antiques», en Mélanges dédiés à Gabriel Marty, Tolouse, I978, pág. 207.

${ }^{51}$ Interpretación que, a nuestro juicio, no resulta arbitraria dado que, a falta de un indicio relativo a la vinculación con el lugar de su primitivo domicilio, convenimos con LE BOHEC, L'Armée romaine sous le Haut-Empire, cit., pág. 92 (- The imperial roman army, cit., pág. 88), en que probablemente tras los largos años de servicio el sentimiento del soldado fuera el de «appartenir au camp et non à la ville ou à la campagne». 
C. Theod. 7.I2.I (Imp. Constantinus A. et C.): Nec cui liceat praepositorum vel decurionum vel tribunorum cohortium quocumque genere cuiquam de militibus a castris atque signis vel his etiam locis, quibus praetendant, discedendi commeatum dare. Si quis vero contra legem facere ausus fuerit et militem contra interdictum commeatu dimiserit atque id temporis nulla eruptio erit, tunc deportatione cum amissione bonorum adficiatur; sin vero aliqua barbarorum incursio extiterit et tunc, cum praesentes in castris atque apud signa milites esse debeant, quisquam afuerit, capite vindicetur ${ }^{52}$.

Asimismo, el régimen domiciliario de Hermogeniano estrechaba el vínculo del soldado con su cuerpo militar al atribuir un domicilio, en el lugar donde se servía en armas, a los sujetos que carecían de una morada estable, como los vagabundos que fueron admitidos en la milicia a partir del siglo IV:

C.Theod. 7.13.6』I (Impp. Valentinianus et Valens AA. ad Modestum P. $P$., año 370): ...Nullus vero tironem vagum aut veteranum possit offerre, cum ad spontaneam singuli militiam propositae inmunitatis commodis invitentur. Circa eos enim legis iubemus velere beneficium, qui indigenas atque ipsius provinciae finibus innutritos vel adfixos censibus vel adcrescentibus suis obtulerint iuniones; neque enim convenit illum inmunitate gaudere, qui vana oblatione vagi atque fugitivi vel veterani filii statum futurae conventionis inviserit.53.

En esta línea parece apuntar Guzmán Brito, el cual interpreta el pasaje de Hermogeniano en el sentido de que "el soldado que no tenga establecimiento posee el domicilio allí donde more ${ }^{154}$, es decir, donde presta servicio.

No obstante, tales sujetos, como señala Giuffrè, fueron excluidos por Justiniano, como se observa en la no recepción en su Código de las constituciones anteriores que los admitían o en sus modificaciones en sentido negativo $0^{55}$. Sin embargo, sí se recogen aquellas disposiciones relativas a la concesión restrictiva del commeatus y las que regulaban los delitos de deserción y transfuguismo ${ }^{56}$, de donde se desprende el mantenimiento de la preocupación porque el soldado no se alejara del lugar de destino.

Al mismo tiempo, también se mantiene la vinculación con el domicilio primitivo como se deduce, no sólo de la recepción en el Digesto del mencionado pasaje de Hermogeniano, sino también de una constitución de Justiniano del año 529 d. C., recogida

${ }^{52}$ GIUfFrè, Letture e ricerche sulla «Res militaris», II, cit., pp. 400 ss., pp. $4 \mathrm{I} 3$ ss. y pp. 424 SS., donde se recogen a su vez las penas con que eran sancionados los occultatores. Pero, como reconoce el autor, estas medidas fueron ineficaces dado que para eludir las sanciones bastaba que los oficiales no concediesen el permiso pero tolerasen la ausencia. Además, como se desprende de una constitución de Honorio y Teodosio del año 4I3 (C. Theod. 7.I8.I6), el militar no era considerado desertor hasta los tres años y su alejamiento era castigado solamente con la perdida de antigüedad. Al respecto, vid. también, VALLEJO GIRVÉS, «Sobre la persecución y el castigo a los desertores en el ejército de Roma», cit., pp. 246 ss., quien señala la creación de oficiales encargados de la captura de estos soldados vagos; JONES, The Later Roman Empire, cit., pág. 633; RICHARDOT, La fin de l'armée romaine (284-476), cit., pp. 267 ss., que analiza el grave problema de la deserción en el ejército del siglo IV d. C.

${ }^{53}$ Vid., asimismo, C. Theod. 7.I8.ıo, del año 400; C. Theod. 7.I8.7, del año 422; C. Theod. 7.20.2, del año 400, entre otras. Al respecto, GIUfFRÈ, Letture e ricerche sulla «Res Militaris», II, cit., pp. 400 ss.

${ }^{54}$ GUZMÁN BRITO, Derecho privado romano, I, cit., pág. 287.

${ }^{55}$ Cfr. C. I. I2.43.I respecto a C. Theod. 7.I3.6. GIUFFRÉ, Letture e ricerche sulla «Res Militaris», II, cit., pág. 42I n. 90.

${ }^{56}$ Recogidas, respectivamente, en el título 43(42), De Commeatu, y en el 46(45), De Desertoribus et occultatoribus eorum, del libro I2. Vid., asimismo, C. I. 7.13.4. 
por Amelotti, en la que el emperador afirmaba que los que se hallasen en una expedición y durante el tiempo de la misma, podrían pedir la restitución por entero, privilegio que cesaba cuando fuera del servicio de la expedición habitaban en otros lugares o en sus casas:

C. I. 2.5I(50).8 (Imp. Iustinianus A. Mennae P.P.): Sancimus, his solis, qui in expeditionibus occupati sunt, ea tantummodo tempora, quae in eadem expeditione percurrunt, tam in exceptionibus declinandis, quam in petendis in integrum restitutionibus eis opitulari; illis temporibus, per quae citra expeditionis necessitatem in aliis locis vel in suis aedibus degunt, minime eos ad vindicanda memorata privilegia adiuvantibus ${ }^{57}$.

Y la misma constitución es reproducida, con idénticos términos, en el Capítulo XXXV, Quibus non obiicitur longi temporis praescriptio, del Libro VII, para insistir, como señala Hernández-Gil, en que los soldados no se hallaban exentos de esta praescriptio durante el tiempo que permanecieran en sus sedes o en otros lugares ${ }^{58}$.

A la vista de esta situación podemos afirmar que también con Justiniano, sólo cuando se destruyera la presunción iuris tantum de que el soldado conservaba el domicilio primitivo, se ubicaba el mismo en el lugar en que estuviera levantado en armas, reforzando de este modo su ligamen con aquel lugar y con su cuerpo militar ${ }^{59}$.

Por tanto, como indicábamos al inicio de este apartado, parece posible que no siempre la atribución de un domicilio a los empleados públicos afirmada por Savigny, anulaba su singularis voluntas (domicilio legal strictus sensus) sino que, en ocasiones, el Derecho público se limitaba a señalar un domicilio ante la ausencia de uno elegido libremente, como ocurre con el domicilio del soldado. Podríamos, en consecuencia, calificar este supuesto como "domicilio legal condicionado".

\section{Apéndice: La no reintegración del domicilium iure postliminii}

Conforme a las leyes romanas, el ciudadano romano que era capturado por el enemigo no se encontraba, en puridad, en una situación de esclavitud, puesto que no perdía totalmente sus derechos, ni se producía una cesación absoluta de su capacidad, sino que sus relaciones jurídicas (tutela, patria potestad, propiedad, obligaciones, derechos económicos) quedaban en suspenso. Si el cautivo volvía a Roma o a una ciudad aliada ${ }^{60}$, teniendo la

${ }^{57}$ AmelotTI, La prescrizione delle azioni in Diritto romano, cit., pág. 92 n. 256.

${ }^{58}$ C. I. 7.35.8. HERNÁNDEZ-GIL, El testamento militar (En torno a un sistema hereditario militar romano), cit., pág. II2; AMELOTTI, La prescrizione delle azioni in Diritto romano, cit., pág. I7 n. 42 y pág. I92 n. 256.

59 Sobre las presunciones como medio de prueba, por todos, GUILLÉn, E.-FABRE, M.C., «La prueba de presunciones en el proceso civil romano y su recepción en el Derecho Civil argentivo», en La prueba y medios de prueba: de Roma al derecho moderno, Actas del VI Congreso Iberoamericano $y$ III Congreso Internacional de Derecho romano, Madrid, 2000, pp. 22I SS.; RASCÓN, C., «La presunción como punto de partida del litigio», en La prueba y medios de prueba: de Roma al derecho moderno, Actas del VI Congreso Iberoamericano y III Congreso Internacional de Derecho romano, Madrid, 2000, pp. 629 ss.; SuRGIK, A., «Das presunçoes como meios de prova (De Roma à atualidade)», en La prueba $Y$ medios de prueba: de Roma al derecho moderno, Actas del VI Congreso Iberoamericano y III Congreso Internacional de Derecho romano, Madrid, 2000, pp. 739 ss.

${ }^{60}$ D. 49.I5.5『I (Pomponius, libro XXXVII. ad Quintum): In bello, quum hi, qui nobis hostes sunt, aliquem ex nostris ceperunt, et intra praesidia sua perduxerunt; nam si eodem bello is reversus fuerit, postliminium habet, id est, perinde omnia restituuntur ei iura, ac si captus ab hostibus non esset; antequam in praesidia perducatur hostium, manet civis; tunc autem reversus intellegitur, si aut ad amicos nostros perveniat, aut intra praesidia nostra esse coepit. 
intención de permanecer en ella ${ }^{6}$, en virtud del ius postliminii, readquiría la libertad y se reintegraba en todos sus derechos pendientes o en suspenso. postliminii ${ }^{62}$.

Regulae Ulpiani, I0.4: cum reversus fuerit, omnia pristina iura recepit iure

Sólo las situaciones de hecho, que no podían interrumpirse, como el matrimonio o la posesión, quedaban extinguidas por la captivitas y no se recuperaban iure postliminii.

D. 49.I5.I4』I (Pomponius, libro III. ad Sabinum): Non ut pater filium, ita uxorem maritus iure postliminii recipit, sed consensu redintegratur matrimonium $^{63}$.

D. 4.6.I9 (Papinianus, libro III. Quaestionum): Denique si emtor, priusquam per usum sibi acquireret, ab hostibus captus sit, placet interruptam possessionem postliminio non restitui, quia haec sine possessione non consistit,

${ }^{61}$ D. 49.I5.5『3 (Pomponius, libro XXXVII. ad Quintum): Captivus autem, si a nobis manumissus fuerit, et pervenerit ad suos, ita demum postliminio reversus intellegitur, si malit eos sequi, quam in nostra civitate manere; et ideo in Atilio Regulo, quem Carthaginienses Romam miserunt, responsum est, non esse eum postliminio reversum, quia iuraverat Carthaginem reversurum, et non habuerat animum Romae remanendi. Et ideo in quodam interprete Menandro, qui, posteaquam apud nos manumissus erat, missus est ad suos, non est visa necessaria lex, quae lata est de illo, ut maneret civis Romanus; nam sive animus ei fuisset remanendi apud suos, desineret esse civis, sive animus fuisset revertendi, maneret civis, et ideo esset lex supervacua. En el mismo sentido, D. 49.15.26. Cfr. Cicerón, pro Balbo, II.28; de orat., I.40.I82, en los que algunos autores se han apoyado para afirmar que el animus remanendi fue introducido con posterioridad.

${ }^{62}$ No obstante, el ius postliminii no se aplicaba cuando el ciudadano romano era un desertor (D. 49.I6.3『2I), un tránsfuga (D. 49.I5.I9 \$4), cuando era capturado por piratas o ladrones (D. 49.15.I9 \2) o en el supuesto de guerra civil o motín (D. 49.I5.2I』I). Sobre el ius postliminii, vid., entre otros, BeCHMAnN, A., Das ius postliminii und die Lex Cornelia, Erlangen, I872, passim; MITTEIS, L., Römisches Privatrecht bis auf die Zeit Diokletians, I, Leipzig, I908 (reimpresión Aalen, I994), pp. I25 SS.; SERTORIO, L., La prigionia di guerra e il diritto di postliminio, Torino, I9I5 (edición anastática Roma, I97I), passim; COSTA, E., Cicerone giurisconsulto, I, Bologna, I927 (edición anastática, Roma, I 964), pp. 276 ss.; AlberTARio, E., «"Postliminium” e “possessio”», en S.D.H.I., 6, I940, pp. 384 ss.; GuARINO, A., «Sul "ius singulare postliminii”», en Z.S.S., 6I, I94I, pp. 58 ss.; SolAZZI, S., «Il concepto dell' “ius postliminii”», en Scritti Ferriri, II, Milano, pp. 288 ss.; idem, «Il "ius postlimini” in Gai. I, I29», en S.D.H.I., 20, I954, pp. 318-320; RASI, P., Consensus facit nuptias, Milano, I946, pp. Io6-I23; AmIRANTE, L., «Captivitas» e «Postliminium», Napoli, I950, passim; idem, «Ancora sulla captivitas e il postilimium», en Studi in onore di Pietro De Francisci, I, I956, pp. 57I ss.; idem, s.v. «postlimio (Diritto romano)», en N.N.D.I., XIII, Milano, I966, pp. 323 ss.; idem, Prigionia di guerra riscatto e postliminium, Lezioni II, Napoli, I970, passim; GIOFFREDI, C., «Sul "ius postliminii”, I, La struttura dell'istituto», en S.D.H.I., I6, I950, pp. I3 SS.; KRELLER, H., «Juristenarbeit am postliminium», en Z.S.S., 69, I952, pp. I72 ss.; KORHARDT, H., «"Postliminium” in republikanischer Zeit», en S.D.H.I., I9, I953, pp. I ss.; BONA, F., «"Postliminium in pace”», en S.D.H.I., 2I, I955, pp. 249 SS; DE VISSHER, F., «Droit de capture et "postliminium in pace"», en R.I.D.A., 3, I956, pp. I97 ss.; LONGO, G., «Postilla critiche in tema di "cautivitas"», en I.U.R.A., 8, I987, pp. 29 ss., RATTI, U., Studi sulla «captivitas», Napoli, I980, passim; KolENDO, J., «Les Romains prisonnier de guerre des Barbares au I ${ }^{\text {er }}$ et au II $^{\mathrm{e}}$ siècles», en Index, I5, I987, pp. 227-234; MAFFI, A., Ricerche sul «postliminium», Milano, I992, passim; CASANI, A.M., La situación jurídica de los hijos de los cautivos de guerra, Valencia, I995, passim; CURSI, M.F., La struttura del «postliminium» nella Repubblica e nel Principato, Napoli, I996, passim; SANNA, M.V., Nuove ricerche in tema di postliminium e redemptio ab hostibus, Cagliari, 200I, passim; D'AMATI, L., Civis ab hostibus captus. Profili del regime classico, Milano, 2004, passim.

${ }^{63}$ D. 49.15 .8 (Paulus, libro III. ad legem Iuliam et Papiam): Non ut a patre filius, ita uxor a marito iure postliminii recuperari potest, sed tunc, quum et voluerit mulier, et adhuc alii post constitutum tempus nupta non est; quodsi noluerit nulla causa probabili interveniente, poenis discidii tenebitur. 
possessio autem plurimum facti habet, causa vero facti non continetur postliminio $^{64}$.

En este contexto, cabe plantearse si el domicilio que tuviera el captivus antes de caer prisionero también quedaba en suspenso y podía recuperarlo a su regreso o si, por el contrario, el mismo se extinguía en situación de cautividad de modo que, en la eventualidad de un posible retorno, debía volver a constituirlo.

Ante la falta de fuentes al respecto, y sin perjuicio de ulteriores estudios, la pérdida del domicilio primitivo nos parece, a priori, la opción más factible puesto que, si bien el domicilio era compatible con ausencias temporales del lugar de establecimiento, el mismo no llegó en ninguna de las etapas del Derecho romano a un grado tal de abstracción que permitiera su conservación indefinida solo animo, exigiéndose en todo momento, tanto para su constitución, como para su conservación y traslado, la residencia material efectiva y la intención actual de permanencia:

C. I. I0.39(40).7 pr.-I (Impp. Diocletianus et Maximianus AA. et CC. Aurelio): Cives quidem origo, manumissio, allectio vel adoptio, incolas vero, sicut et divus Hadrianus edicto suo manifestissime declaravit, domicilium facit. Et in eodem loco singulos habere domicilium non ambigitur, ubi quis larem rerumque ac fortunarum suarum summam constituit, unde rursus non sit discessurus, si nihil avocet, unde quum profectus est, peregrinari videtur, quod si rediit, peregrinari iam destitit.

D. 50.I.20 (Paulus libro XXIV. Quaestionum): Domicilium re et facto transfertur, non nuda constestatione ${ }^{65}$.

En este sentido, el domicilio se aproxima al matrimonio clásico, cuyo mantenimiento (matrimonium in facto esse) requería un consentimiento continuo o affectio maritalis, que sólo cobraba sentido a través de su exteriorización (honor matrimonii), por lo que dicho consentimiento no podía desligarse con carácter absoluto de la convivencia (consuetudo individuae vitae) ${ }^{66}$. En caso de cautividad del esposo, al no existir esa comunidad de vida exteriormente apreciable, en que se traducía el matrimonio, éste no podía subsistir aunque, como nos indica Trifonino, la esposa permaneciera en casa del marido cautivo como domicilio del matrimonio:

${ }^{64}$ D. 4I.3.I5 (Paulus, libro XV. ad Plautium): Si is, qui pro emtore possidebat, ante usucapionem ab hostibus captus sit, videndum est, an heredi eius procedat usucapio, -nam interrumpitur usucapio-, et si ipsi reverso non prodest, quemadmodum heredi eius proderit. Sed verum est, eum in sua vita desiisse possidere; ideoque nec postliminium ei prodest, ut videatur usucepisse; D. 49.I5.29 (Labeo, libro VI. Pithanon a Paulo epitomatorum): Si postliminio rediisti, nihil, dum in hostium potestate fuisti, usucapere potuisti. Paulus: imo si quid servus tuus peculii nomine, dum in eo statu esses, possederit, id eo quoque tempore usucapere poteris, quoniam eas res etiam inscientes usucapere solemus; et eo modo etiam hereditas, nondum nato postumo, aut nondum adita augeri per servum hereditarium solet.

${ }^{6}$ En este sentido nos remitimos a lo expuesto en, LÓPEZ HUGUET, «Un estudio sobre la configuración jurídica del término domicilium en Derecho romano», cit., pp. I ss.

${ }^{66}$ Tras las aportaciones de MANETI, C., Della inoponibilità delle condizioni ai negozi giuridici, ed in specie delle condizioni apposte al matrimonio, Siena, I889, pp. 40 ss., fueron muchos los autores que consideraron a la convivencia como un requisito esencial, si bien entendida por algunos en sentido material y por otros en sentido ético. Sin embargo, tras los escritos de VOLTERRA, E., La conception du mariage d'aprés les juristes romains, Padua, I940, pp. 33 ss. y ORESTANO, R., La struttura giuridica del matrimonio romano, Milano, I95I, pp. 85 ss., pp. I49 ss. y pp. I87 ss., creció el sector doctrinal que consideraba al consensus como el único requisito esencial. A nuestro juicio, las posturas mantenidas no son tan distintas dado que, en realidad, ambos elementos no se daban separadamente. El consensus no se puede interpretar en el sentido de absoluta espiritualidad separado de la convivencia y ésta no puede ser entendida en el sentido de que debiese durar per momenta y un cónyuge no pudiese vivir transitoriamente separado del otro. 
D. 49.I5.I2』4 (Thyphoninus, libro IV. Disputationum): sed captivi uxor, tametsi maxime velit, in domo eius sit, non tamen in matrimonio est ${ }^{67}$.

Y la misma conexión encontramos entre el domicilio y la possessio que también requería para su adquisición y conservación la concurrencia del corpus (tenencia material de la cosa) y del animus (intención de tener la cosa para sí con exclusión de los demás):

D. 4I.2.3.I (Paulus, libro LIV. ad Edictum): Et adipiscimur possessionem corpore et animo, neque per se animo, aut per se corpore. Quod autem diximus, et corpore, et animo acquirere nos debere possessionem, non utique ita accipiendum est, ut, qui fundum possidere velit, omnes glebas circumambulet; sed sufficit, quamlibet partem eius fundi introire, dum mente et cogitatione hac sit, uti totum fundum usque ad terminum velit possidere.

D. 4I.2.8 (Paulus, libro LXV. ad Edictum): Quemadmodum nulla possessio acquiri, nisi animo et corpore potest, ita nulla amittitur, nisi in qua utrumque in contrarium actum est ${ }^{68}$.

La captivitas en manos de los enemigos provocaba la interrupción de la posesión, dado que el prisionero no podía cumplir ninguno de los dos requisitos. Por ello, como afirma Papiniano, durante el estado de cautividad no se podía completar la usucapión sobre una cosa, ya que se entendía que el capturado no la había poseído, ni se consideraba adquirida por el postliminio:

D. 4I.3.44.7 (Papinianus, libro XXII. Quaestionum): Si, quum apud hostes dominus aut pater agat, servus aut filius emat, an et tenere incipiat? Si quidem ex causa peculii possedit, usucapionem inchoari, nec impedimento domini captivitatem esse, cuius scientia non esset in civitate necessaria; si vero non ex causa peculii comparetur, usu non capi, nec iure postliminii quaesitum intelligi, quum prius esset, ut, quod usucaptum diceretur, possessum foret; sin autem pater ibi decesserit, quia tempora captivitatis ex die, quo capitur, morti iungerentur, potest filium dici et possedisse sibi, et usucepisse intelligi ${ }^{69}$.

${ }^{67}$ Sobre la disolución del matrimonio del captivus, entre otros, DumonT, F., Manuel de Droit Romain, I, Paris, I947, pág. 294, afirma que sólo en el Bajo Imperio se mantendrá salvo que transcurran cinco años sin tener noticias del capturado; ORESTANO, La struttura giuridica del matrimonio romano, cit., pp. I38 ss.; LONGO, «Postilla critiche in tema di “cautivitas"», cit., pp. 33 ss.; ARIAS BONET, J.A., «La no reintegración iure postliminii del matrimonio romano», en A.H.D.E., 25, I955, pp. 567 ss.; AMIRANTE, Prigionia di guerra, riscatto e postliminium, cit., pág. 70; CARAMES FERRO, J.M., Instituciones de derecho privado romano, I, $2^{\text {a }}$ edición, Buenos Aires, I972, pág. 59, para quien sólo con Justiniano se permite recuperarlo por postliminio; RATTI, Studi sulla «captivitas», cit., pp. I50 ss.; URSO, P., Il matrimonio del prigioniere in Diritto romano, Roma, I992, pp. 5 SS.; CURSI, La struttura del postliminium nella Repubblica e nel Principato, cit., pp. 37 ss., pp. 308 y pág. 333; GIUNTI, P., Consors Vitae. Matrimonio e ripudio in Roma antica, Milano, 2004, pp. I49 ss.

${ }^{68}$ Sólo en casos excepcionales la posesión pudo conservarse con carácter temporal sólo por el ánimo. Sobre la posesión, CANNATA, C.A. Possessio, possessor, possidere nelle fonti giuridiche del basso impero romano, Milano, I962, pág. I4I; idem, s.v. «possessio (Diritto romano)», en N.N.D.I., XIII, Torino, I966, pp. 323 ss.; CARCATERrA, A., Possessio. Ricerche di storia e di dommatica, Roma, I967, passim; FABI, B., Aspetti del possesso romano, Roma, I972, passim; LAMBRINI, P., L'elemento soggettivo nelle situazioni possessorie del Diritto romano, Padova, I998, passim; NICOsIA, G., Problemi possessori, Catania, I997, pp. I90-I93 y pág. 205; IHERING, R., La teoría de la posesión: el fundamento de la protección posesoria, trad. esp. de A. Posada, Madrid, 2004, passim; SAVIGNY, F., Tratado de la posesión según los principios del Derecho romano, trad. esp. de J.L. Moreno Pérez, Granada, 2005, pp. I35 ss. y págas. 2II ss. y la bibliografía por ellos citada.

${ }^{69}$ Sólo la posesión del esclavo o hijo ex causa peculari permitía al cautivo adquirir la cosa si lograba retornar. En otro caso, la cautividad por guerra impedía la uscapión al interrumpir la posesión que no se recuperaba por postliminio. Vid., en este sentido D. 49.I5.29; D. 49.I5.22 3 ; D. 4I.3.I5. 
En conclusión, las similitudes apuntadas entre estas situaciones de hecho y el domicilio, que no podía desligarse absolutamente de su elemento material, nos conducen a pensar que tampoco éste podría recuperarse iure postliminii. No obstante, como indicábamos supra, se trata de una hipótesis de trabajo sobre la que seguiremos profundizando.

Albertario, E., Possesso e quasi possesso, Milano, I940, pp. II3 ss.; AMIRANTE, s.v. «postliminio (Diritto romano)», cit., pp. 432; CURSI, La struttura del postliminium nella Repubblica e nel Principato, cit., pp. 243 ss.; CASANI, La situación jurídica de los hijos de los cautivos de guerra, cit., pp. I30 ss.; NiCosia, Problemi possessori, cit., pp. I93 ss.; SAVIGnY, Tratado de la posesión según los principios del Derecho romano, cit., pp. 229 ss. 